\title{
Synthesis and Characterization of Low Viscosity Aromatic Hyperbranched Polyester Epoxy Resin
}

\author{
Daohong Zhang ${ }^{1,2,3 *}$, Demin Jia ${ }^{2 *}$, and Zihu Zhou ${ }^{3}$ \\ ${ }^{1}$ Key Laboratory of Catalysis and Materials Science of the State Ethnic Affairs Commission \& Ministry of Education, \\ Hubei Province, South-central University for Nationalities, Wuhan, Hubei 430074, China \\ ${ }^{2}$ College of Materials Science and Engineering, South China University of Technology, Guangzhou,Guangdong 510641, China \\ ${ }^{3}$ Guangzhou Supe Chemical Co., LTD, Guangzhou, Guangdong 510641, China
}

Received November 28, 2007; Revised October 23, 2008; Accepted November 12, 2008

\begin{abstract}
Low viscosity aromatic hyperbranched polyester epoxy resin (HTBE) was synthesized by the reaction between epichlorohydrin (ECH) and carboxyl-end hyperbranched polyester (HTB) which was prepared from inexpensive materials $A_{2}$ (1,4-butanediol glycol, BEG) and $B_{3}$ (trimellitic anhydride, TMA) by pseudo one-step method. The molar mass of the HTB was calculated from its acid value by "Recursive Probability Approach". The degree of branching (DB) of the HTB was characterized by model compounds and ${ }^{1} \mathrm{H}$ NMR-minus spectrum technology, and the DB of the HTB was about 0.47 0.63. The viscosity and epoxy equivalent weight of the HTBE were 3,600 5,000 cp and lower than $540 \mathrm{~g} / \mathrm{mol}$ respectively. The reaction mechanism and structure of the $\mathrm{AB}_{2}$ monomer, HTB and HTBE were investigated by MS, ${ }^{1} \mathrm{H}$ NMR and FTIR spectra technology. The molecular size of HTBE is under 8.65 $\mathrm{nm}$ and its shape is ellipsoid-like as determined by molecular simulation.
\end{abstract}

Keywords: hyperbranched epoxy resin, low viscosity, degree of branching, molecular simulation.

\section{Introduction}

Epoxy resin is widely used as one of the important thermosetting resins. The current trend of its development is towards "solventless", "functionality" and "toughening and reinforcing". 1

Hyperbranched epoxy resins are of special interest as their easy synthetic accessibility, low viscosity, high solubility, large number of functional groups, allows for their production in large quantities and application on an industrial scale. In the literature, a number of different synthetic approaches of the predominant hyperbranched epoxy resins have been reported, including end group modification of hyperbranched polymers, ${ }^{2,3}$ proton transfer polymerization, ${ }^{4-7}$ end functionalization of hyperbranched poly(siloxysilane) ${ }^{8}$ and functionalization of poly(methyl acrylate) by ATRP. ${ }^{9}$ However, all these hyperbranched epoxy resins were either solid or high viscosity liquid and would need dilution with organic solvent, which is detrimental to environment. These types of hyperbranched epoxy resins thus were only used as toughener of common epoxy resin. ${ }^{10-12}$ Several folds increase in fracture toughness was obtained for a commercial DGEBA epoxy resin using only $5 \%$ by weight of a hyperbranched epoxy

*Corresponding Authors. E-mails: zhangdh27@163.com or psdmjia@scut.edu.cn resin toughener, ${ }^{11}$ but their strength was found to decrease to some extent because of the low crosslinking density. In 2006, we ${ }^{13,14}$ reported two kinds of low viscosity aromatic polyester hyperbranched epoxy resins with low epoxy equivalent weight which not only increased toughness of diglycidyl ether of bisphenol-A (DGEBA) but also increased its tensile strength and flexural strength remarkably.

Some preparation technology of hyperbranched epoxy resins was based on expensive raw materials and relatively complex synthetic process. ${ }^{2-9}$ There are few literature available on the synthesis of economically inexpensive low-viscosity liquid hyperbranched epoxy resin. The present paper reports the synthesis and detailed characterization of a carboxyl-end hyperbranched polymer and a low-viscosity liquid hyperbranched epoxy resin from lower cost materials and simple technology.

\section{Experimental}

Materials and Instrumentation. Trimellitic anhydride (TMA), 1,4-butanediol glycol (BEG), tetrabutyl titanate (TBT), epichlorohydrin (ECH), diglycidyl ether of bisphenol A (DGEBA) containing $5.1 \mathrm{mmol}$ epoxy group per gram of resin and other organic solvents were commercially purchased.

${ }^{1} \mathrm{H}$ NMR measurements were carried out on a $400 \mathrm{MHz}$ 
Bruker NMR spectrometer with DMSO- $\mathrm{d}_{6}$ as solvent. FTIR measurements were performed on a Bruker Vector 33 spectrometer using sealed cell ( $\mathrm{KBr} 0.5 \mathrm{~mm})$. A double focusing mass spectrometer (VG ZAB-HS) was used to obtain the fast atom bombardment ion mass spectrum on the base of 3nitrobenzylalcohol. The viscosity of the HTBE was measured by a Brookfield DV-II+ Viscometer with RV-S06 spindle in $25^{\circ} \mathrm{C}$ and $20 \mathrm{rpm}$.

Synthesis of Low-Viscosity Hyperbranched Polyester Epoxy Resin (HTBE).

Synthesis of $\mathbf{A B}_{\mathbf{2}}$ Monomer: $0.1 \mathrm{~mol}$ TMA, $0.1 \mathrm{~mol} \mathrm{BEG}$ and $100 \mathrm{~mL}$ 1,4-dioxane as solvent were charged in a 4necked reaction flask equipped with stirrer, cooler, thermometer and nitrogen inlet and were reacted for $3 \mathrm{~h}$ at $120^{\circ} \mathrm{C}$, and then the white solid $\mathrm{AB}_{2}$ monomer with acid value of $391.40 \mathrm{mg} \mathrm{KOH} / \mathrm{g}$ was obtained after the solvent was removed under a pressure of $3 \sim 5 \mathrm{mmHg}$ at $120^{\circ} \mathrm{C}$ for $30 \mathrm{~min}$.

Synthesis of Model Compound 1,2,4-tri(4-Hydroxylbutyl) Benzoate (TTB): 0.1 mol TMA, 0.4 mol BEG, 0.005 mol TBT and $100 \mathrm{~mL}$ 1,4-dioxane as solvent were charged in a 4-necked reaction flask equipped with stirrer, cooler, thermometer and nitrogen inlet and were reacted for $3 \mathrm{~h}$ at 150 $160^{\circ} \mathrm{C}$, and then the white solid model compound TTB with acid value under $3 \mathrm{mg} \mathrm{KOH} / \mathrm{g}$ was obtained after the solvent was removed under a pressure of $3 \sim 5 \mathrm{mmHg}$ at
$120{ }^{\circ} \mathrm{C}$ for $40 \mathrm{~min}$.

Synthesis of Hyperbranched Polyester (HTB): The HTB was prepared by pseudo one-step method as shown in Figure 1. Detailed process was reported in ref.15.

Synthesis of Low-Viscosity Hyperbranched Polyester Epoxy Resin (HTBE): The HTBE was prepared by the reaction between ECH and HTB and shown in Figure 1. Detailed process was reported in ref.15.

\section{Results and Discussion}

Structure and Characterization of the $\mathbf{A B}_{2}$ Monomer. Theoretically, the reaction of TMA with BEG produces two $\mathrm{AB}_{2}$ monomer TB-1 and TB-2 with different structure (Figure 2), small amout of TMA-BEG-TMA can also be obtained.

The FTIR spectra of TMA, BEG and the $\mathrm{AB}_{2}$ monomer are shown in Figure 3. The appearance of the strong absorption peak at $1710 \mathrm{~cm}^{-1}$ and the disappearance of the broad and strong absorption peak at 1720 and $1779 \mathrm{~cm}^{-1}$ from the anhydride group confirm that the anhydride group has reacted completely. From the mass spectrum of the $A_{2}$ monomer in Figure 4, the molecular ion peak of the monomer $\mathrm{AB}_{2}$ and TMA-BEG-TMA are observed at the 281 and 473 respectively which confirms the structure of the $A B_{2}$ monomer and the TMA-BEG-TMA compound.

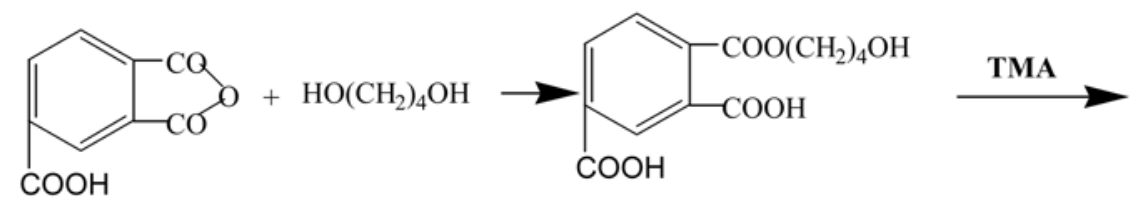

(TMA)

(BEG)

(TB)

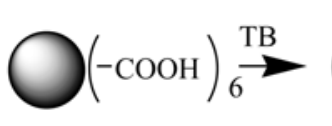

(HTB-1)<smiles>CC1(C(=O)OCC(O)C(Cl)Cl)CCCCC1</smiles>

(HTBE-1-M)

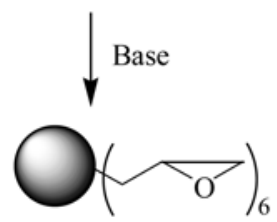

(HTBE-1)

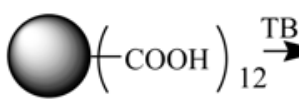

(HTB-2)<smiles>ClCC1CO1</smiles>

(HTB-3)<smiles>ClCC1CO1</smiles><smiles>CC1(C(=O)OCC(O)Cl)CCCCC1</smiles>

(HTBE-2-M)

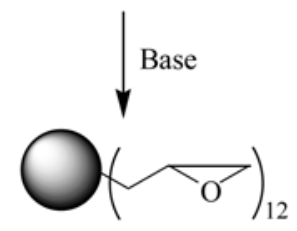

(HTBE-2)

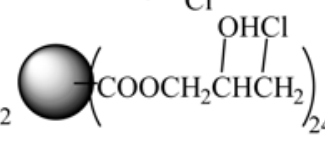

(HTBE-3-M)

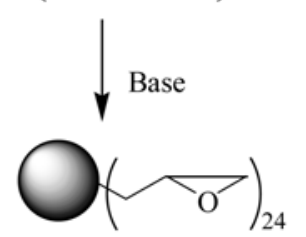

(HTBE-3)

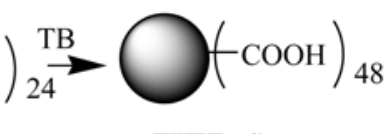

(HTB-4)<smiles>ClCC1CO1</smiles><smiles>CC1(C(=O)OCC(O)Cl)CCCCCC1</smiles>

(HTBE-4-M)

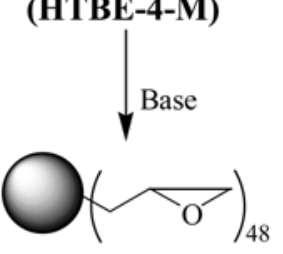

(HTBE-4)

Figure 1. Synthetic scheme of hyperbranched epoxy resin HTBE. 
<smiles>O=C(O)c1ccc(C(=O)O)c(C(=O)OCCCCO)c1</smiles>

(TB-1)<smiles>O=C(O)c1ccc(C(=O)OCCCCO)c(C(=O)O)c1</smiles>

(TB-2)

Figure 2. Structure of TB-1 and TB-2 $\mathrm{AB}_{2}$ monomers.

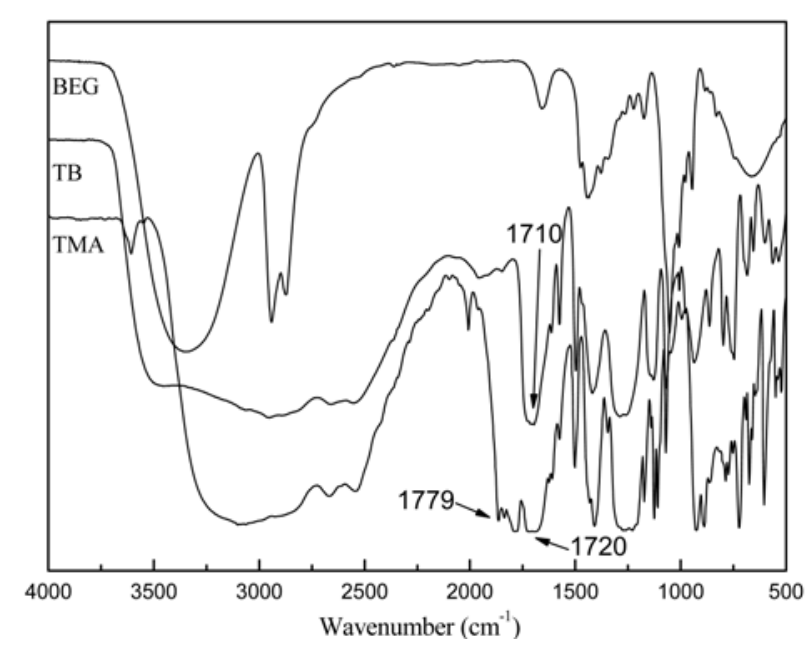

Figure 3. FTIR spectra of TMA, BEG and $\mathrm{AB}_{2}$ monomer.

The ${ }^{1} \mathrm{H}$ NMR spectrum of the $\mathrm{AB}_{2}$ monomer in DMSO-d6 (Figure 5) reflects $\mathrm{C}_{3}-\mathrm{H}$ resonances peak at $\delta 7.7 \sim 7.8 \mathrm{ppm}$, $\mathrm{C}_{6}-\mathrm{H}$ and $\mathrm{C}_{5}-\mathrm{H}$ resonances peak at $\delta 8.1 \sim 8.3 \mathrm{ppm}$ of phenyl hydrogen proton, $-\mathrm{CH}_{2}-(\delta 1.4,1.7,3.4$ and $4.3 \mathrm{ppm})$ and -OH ( $\delta 3.5$ ppm) groups. ${ }^{16}$

Characterization of Hyperbranched Polyester (HTB). The ${ }^{1} \mathrm{H}$ NMR spectra of the HTB obtained by the pseudo one-step method are shown in Figure 6. Comparing the ${ }^{1} \mathrm{H}$ NMR spectrum of the $\mathrm{AB}_{2}$ monomer with the ${ }^{1} \mathrm{H}$ NMR spectra of the HTB, the proton of $-\mathrm{OH}$ group peaks at 3.5

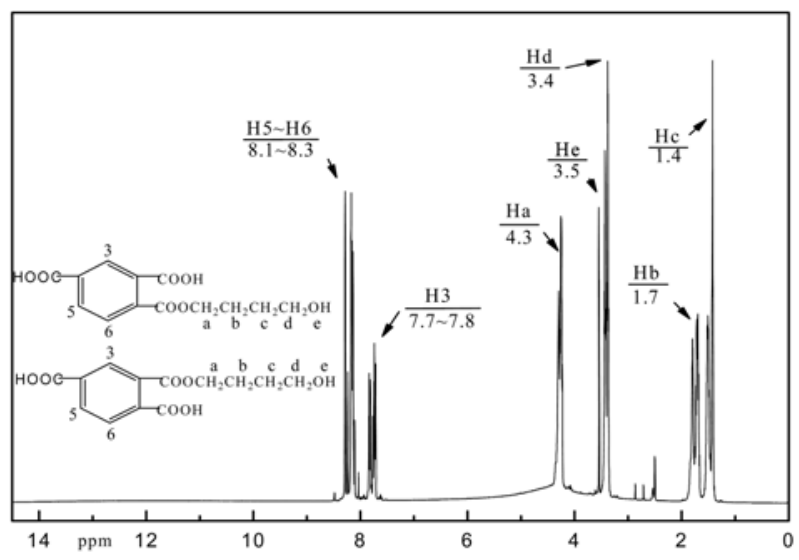

Figure 5. ${ }^{1} \mathrm{H}$ NMR spectrum of $\mathrm{TB} \mathrm{AB}_{2}$ monomer.

ppm disappeared and the proton of $-\mathrm{COOCH}_{2} \mathrm{CH}_{2}$ - group peaks at $4.3 \mathrm{ppm}$ and $1.7 \mathrm{ppm}$ become stronger, these information confirm that the hydroxy group of the compounds has been reacted completely. The appearance of the weak peaks at 2.5 3.0 ppm should be attributed to the proton of the $-\mathrm{OCH}_{2} \mathrm{CH}_{2} \mathrm{CH}_{2} \mathrm{CH}_{3}$ group from TBT catalyst and DMSO- $\mathrm{d}_{6}$.

According to the polymerization mechanism of the HTB and the definition of the $\mathrm{DB},{ }^{7,17,18}$ the resulting HTB contains the following units (Figure 7): (1) branched units $\left(N_{b}\right)$, (2) linear units $\left(N_{L}\right)$ and (3) terminal units $\left(N_{t}\right)$.

The DB is the ratio of branched and terminal units to total units, i.e.

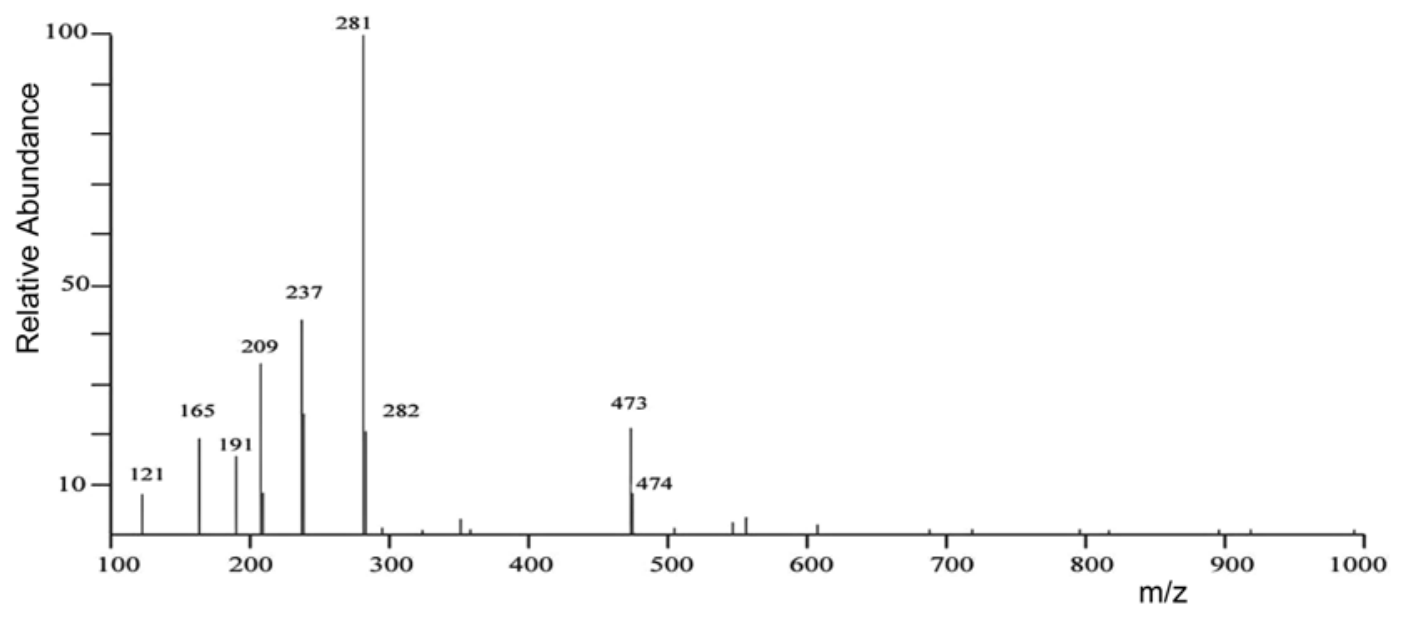

Figure 4. Fast atom bombardment ion mass spectrum of $\mathrm{AB}_{2}$ monomer. 


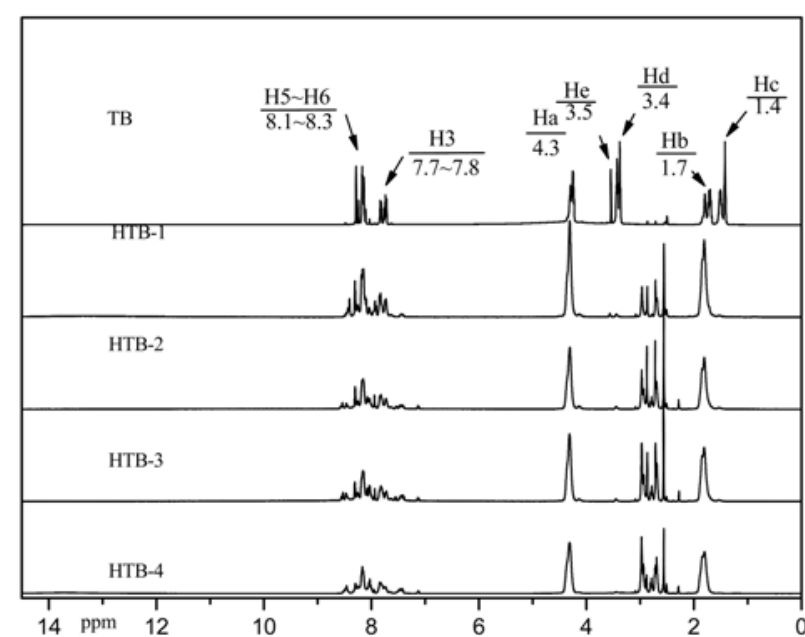

Figure 6. ${ }^{1} \mathrm{H}$ NMR spectra of the $\mathrm{HTB}$ and the $\mathrm{AB}_{2}$ monomer.

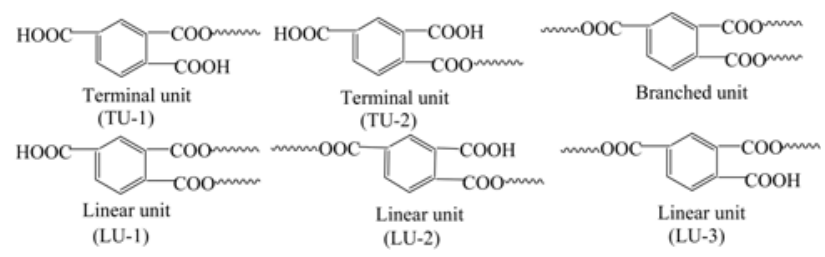

Figure 7. Structure of terminal, branched and linear units.

$$
D B=\left(N_{b}+N_{t}\right) /\left(N_{b}+N_{t}+N_{L}\right)
$$

NMR spectroscopy represents an important tool for the characterization of hyperbranched polymers since detailed analysis of the spectra permits extracting of information on both the degree of polymerization and the extent of branching. Therefore, it is appropriate to discuss the results of this method in detail. Hydrogen protons of phenyl demonstrate different chemical shift according to their structure. The proton signals of $\mathrm{C}_{3}-\mathrm{H}$ appear at 7.7 7.8 ppm, and those of $\mathrm{C}_{5}-\mathrm{H}$ and $\mathrm{C}_{6}-\mathrm{H}$ appear between 8.1 and 8.3 ppm (Figure 6). The chemical shift of $\mathrm{C}_{3}-\mathrm{H}$ proton depends on the substitution groups on neighboring carbon atom $\left(\mathrm{C}_{2}\right.$ and $\left.\mathrm{C}_{4}\right)$. So, the proton signals of $\mathrm{C}_{3}-\mathrm{H}$ may be used to infer the degree of branching of HTB. Chemical structure of model compound TTB is similar to that of branching unit of HTB; therefore,

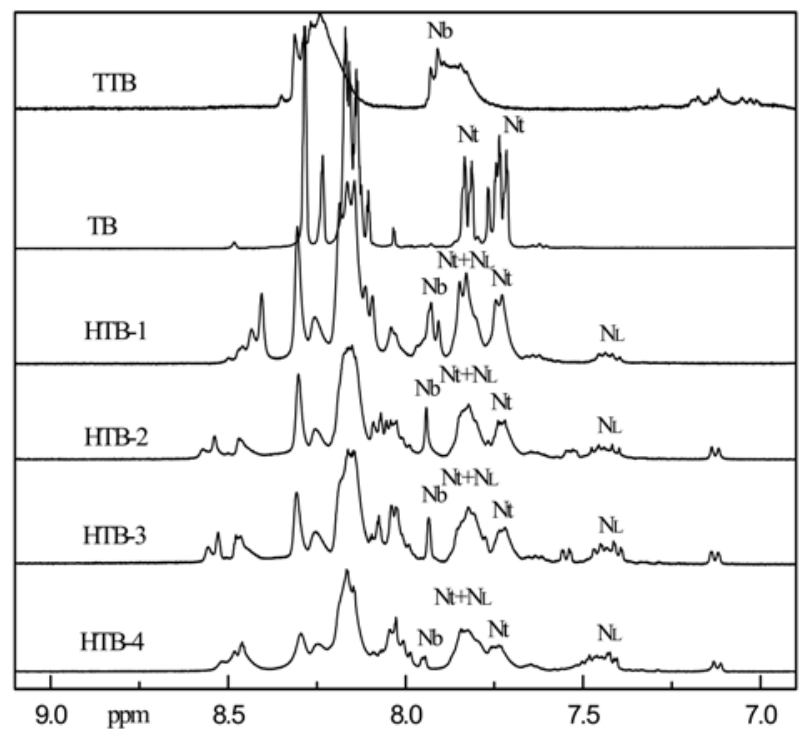

Figure 8. ${ }^{1} \mathrm{H}$ NMR spectra of TTB,TB and HTB- $n(n=1,2,3,4)$ between $7.2 \sim 8.9 \mathrm{ppm}$.

the $\mathrm{C}_{3}-\mathrm{H}$ proton signals of TTB at $7.90 \mathrm{ppm}$ should be those of the branching unit of HTB which appears as single peak since it has only one chemical structure (Figure 8). Moreover, Chemical structure of $\mathrm{TB}\left(\mathrm{AB}_{2}\right.$ monomer $)$ is similar to that of the terminal unit of $\mathrm{HTB}$, and all the $\mathrm{C}_{3}-\mathrm{H}$ proton signals of TB and terminal unit of HTB appear between 7.73 $\sim 7.78 \mathrm{ppm}$ and 7.81 7.85 ppm with two multiple peaks from two chemical structure (TU-1 and TU-2 in Figure 7). The peak area ratio of $7.73 \sim 7.78 \mathrm{ppm}$ to $7.81 \sim 7.85 \mathrm{ppm}$ should be remain constant since all the B-groups of TB-1 and TB-2 are equally reactive. ${ }^{18,19}$ While there are three linear units LU-1, LU-2 and LU-3, the chemical structure of LU-1 is similar to that of $\mathrm{LU}-2$, the $\mathrm{C}_{3}-\mathrm{H}$ proton signals of linear units of HTB should appear as two multiple peaks. Peak area of linear unit chemical shift may be obtained by ${ }^{1} \mathrm{H}$ NMR-minus spectrum technology, ${ }^{16}$ and that is to say, peak area of linear unit chemical shift is equal to the peak area of the branching and terminal units subtracts the $\mathrm{C}_{3}-\mathrm{H}$ proton signals of HTB. According to the above analysis, calculation data of different chemical structure units are obtained and shown in Table I, and degree of branching of

Table I. DB of HTB-1, HTB-2, HTB-3 and HTB-4 and Their Calculational Data

\begin{tabular}{ccccccc}
\hline$\delta(\mathrm{ppm})$ & $\begin{array}{c}7.39 \sim 7.50 \\
N_{L}\end{array}$ & $\begin{array}{c}7.71 \sim 7.77 \\
N t\end{array}$ & $\begin{array}{c}7.78 \sim 7.84 \\
N t\end{array}$ & $\begin{array}{c}7.78 \sim 7.84 \\
N_{L}\end{array}$ & Nb & DB \\
\hline TTB & & & & & & \\
TB & & 0.59 & 0.41 & & & \\
HTB-1 & 0.12 & 0.25 & 0.17 & 0.25 & 0.21 & 0.63 \\
HTB-2 & 0.20 & 0.24 & 0.17 & 0.27 & 0.12 & 0.53 \\
HTB-3 & 0.23 & 0.26 & 0.18 & 0.23 & 0.10 & 0.54 \\
HTB-4 & 0.23 & 0.23 & 0.16 & 0.30 & 0.08 & 0.47 \\
\hline
\end{tabular}


HTB also be calculated.

The molecular weight is very important data for the HBP. According to the polycondensation between hydroxy group and carboxy group, the acid value of the HTB can be used to calculate the degree of polymerization and further reckon the number-average molecular weight. Explicit relationships about theoretical average degrees of polymerization and average molar masses are established in $A B_{f}+B_{g}$ monomer polymerization case by "Recursive Probability Approach”, ${ }^{20}$ and $\bar{X}_{w}, \bar{X}_{n}, \bar{M}_{n}, p_{A}$ and PDI satisfy the following relationships:

$$
\begin{aligned}
& \bar{X}_{w}=1+\frac{2 p_{A}(f+g x)\left[f\left(1-p_{A}\right)+g x\right]+p_{A}^{2}[f(f-1)+g x(g-1)]}{(1+x)\left[f\left(1-p_{A}\right)+g x\right]^{2}} \\
& \bar{M}_{n}=M_{0}+18+\bar{X}_{n}\left(M_{A B 2}-18\right)
\end{aligned}
$$

Here, $\bar{X}_{w}$ and $\bar{X}_{n}$ refer weight-average degree and number-average degree of polymerization respectively. $\bar{M}_{n}$ refers number-average molar mass respectively. $p_{A}$ refers fraction of A groups that have reacted, and PDI refers polydispersity index. $x$ refers the ratio of the core $B_{g}$ to $A B_{2}$ monomer. $M_{0}$ and $M_{A B 2}$ refer molar mass of $B_{g}$ and $A B_{2}$ monomers respectively.

Acid value $\left(A_{v}\right)$ refers to the milligram number of the $\mathrm{KOH}$ needed to neutralize one gram of resin. In the system, $p_{B}, A_{v}$ and $\bar{X}_{n}$ satisfy the following relationships:

$$
\begin{aligned}
A_{v} & =\frac{56,100\left(3+\bar{X}_{n}\right)}{192.12+282.24 \bar{X}_{n}-18\left(\bar{X}_{n}-1\right)} \\
p_{B} & =\frac{\bar{X}_{n}}{2 \bar{X}_{n}+3}
\end{aligned}
$$

Therefore, the relationship of $A_{v}$ and $p_{B}$ satisfy the following eqation:

$$
p_{B}=\frac{168,300-210.12 A_{v}}{168,300+372.48 A_{v}}
$$

In the system, since $p_{A}=f p_{B}, f=2, g=3$, so from the eq. (2) eq. (6), the molecular weight can be calculated and are shown in Table II. Table II illustrates that $\bar{M}_{n}$ of HTB calcuated by "Recursive Probability Approach" are almost equal to their theoretical molar mass. The relationship also confirms that the hydroxyl group of the compounds were reacted completely, consistent to disappearance of hydroxyl proton signal peak of the HTB at 3.5 ppm in Figure 6.

Characterization of HTBE. The preparation mechanism of the HTBE comprises of the ring-open reaction between the HTB and ECH and the ring-close reaction of dehydrohalogenation. Therefore, the molecular weight of HTBE is

\begin{tabular}{|c|c|c|c|c|}
\hline Polymer No. & HTB-1 & HTB-2 & HTB-3 & HTB-4 \\
\hline Theoretical acid value (mg KOH/g) & 335.65 & 260.10 & 233.78 & 222.53 \\
\hline Experimental acid value (mg KOH/g) & 337.73 & 256.27 & 233.39 & 224.41 \\
\hline$p_{B}$ & 0.331 & 0.434 & 0.467 & 0.481 \\
\hline$x$ & $1 / 3$ & $1 / 9$ & $1 / 21$ & $1 / 45$ \\
\hline $\bar{X}_{n}$ & 2.94 & 9.86 & 21.23 & 37.97 \\
\hline $\bar{X}_{w}$ & 3.25 & 12.17 & 40.09 & 123.16 \\
\hline $\mathrm{PDI}=\bar{X}_{w} / \bar{X}_{n}$ & 1.11 & 1.23 & 1.89 & 3.22 \\
\hline PDI from GPC & 1.07 & 2.56 & 2.36 & 2.29 \\
\hline Molar mass from GPC & $1,265.00$ & $2,221.00$ & $3,146.00$ & $3,513.00$ \\
\hline Theoretical molar mass & $1,002.84$ & $2,588.28$ & $5,759.16$ & $12,100.92$ \\
\hline $\bar{X}_{n}$ & 986.99 & $2,815.53$ & $5,819.94$ & $10,243.31$ \\
\hline
\end{tabular}
decided by the corresponding molecular weight of the HTB and the number of their epoxy group. The qualitative analysis of the epoxy group is shown in Figure 9. From Figure 9,

\section{Table II. Properties of the Carboxyl-End Hyperbranched Polymers (HTB)}

Table III. Properties of Hyperbranched Epoxy Resins HTBE

\begin{tabular}{ccccccc}
\hline HTBE & $\begin{array}{c}\text { Molecular Weight } \\
\text { from GPC }\end{array}$ & $\begin{array}{c}\text { Theoretical } \\
\text { Molecular Weight }\end{array}$ & $\begin{array}{c}\text { Molecular Weight } \\
\text { Distribution from GPC }\end{array}$ & $\begin{array}{c}\text { Epoxy Equivalent } \\
\text { Weight (g/mol) }\end{array}$ & $\begin{array}{c}\text { Ring-Close Degree } \\
\text { (\%) }\end{array}$ & $\begin{array}{c}\text { Viscosity } \\
\text { (cp) }\end{array}$ \\
\hline HTBE-1 & 1,944 & 1,339 & 1.64 & 429.2 & 52.1 & 3,600 \\
HTBE-2 & 2,505 & 3,260 & 1.62 & 456.6 & 59.5 & 4,500 \\
HTBE-3 & 3,203 & 7,103 & 1.59 & 540.5 & 54.7 & 5,000 \\
HTBE-4 & 3,635 & 14,789 & 1.64 & 500.0 & 61.5 & 4,900 \\
\hline
\end{tabular}




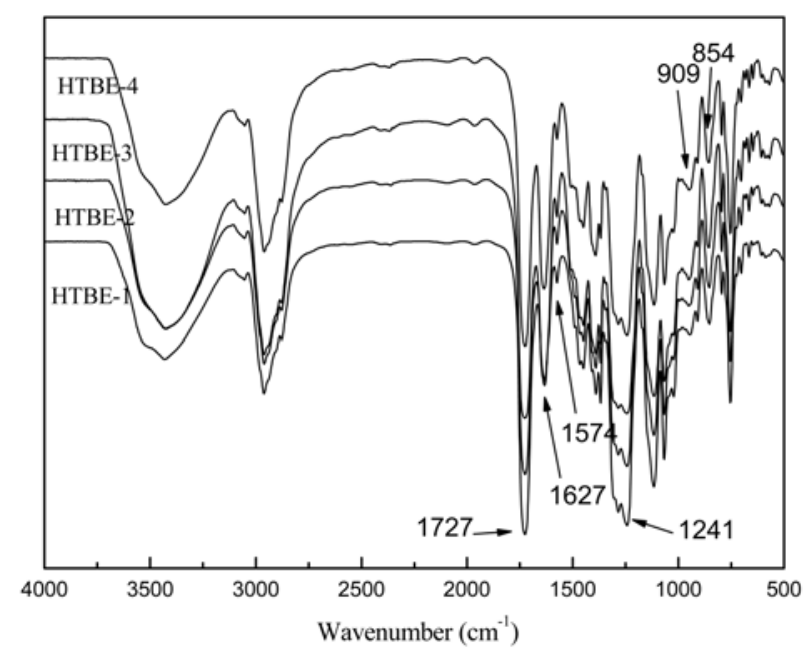

Figure 9. FTIR spectra of the HTBE- $n(n=1,2,3,4)$.

all absorption peaks of the phenyl at 1627, 1574 and 1493 $\mathrm{cm}^{-1}$, the epoxy group at 1241,909 and $854 \mathrm{~cm}^{-1}$ and the -COO- group at $1727 \mathrm{~cm}^{-1}$ are observed. ${ }^{16}$ The quantitative analysis of the epoxy group (Table III) is measured by titration method with hydrochloric acid-acetone solution, other properties also are shown in Table III.

The main characteristics of the HTBE are the low epoxy equivalent weight and low viscosity. Low epoxy equivalent weight can increase the curing rate and crosslinking density. Low viscosity property of the HTBE discards the use of organic solvents. Moreover, the viscosity of the HTBE reaches a maximum with the increase of the generation or molecular weight, and the minimum viscosity of the HTBE-1 is only 3,600 cp, much lower than the values reported. The relationship between the viscosity and the generation of the HTBE confirms that the structure of the HTBE is hyperbranched and possesses high $\mathrm{DB}^{21,22}$ Low viscosity is attributed to the less hydromechanical volume and the high DB of the HBP. For the same molecular weight, the viscosity of HBP decreases with the decrease of hydromechanical volume and the increase of DB; the hydromechanical volume decreases with the increase of DB as well. ${ }^{1,22}$

Figure 10 shows that molecular simulation size of all four kinds of hyperbranched epoxy resins belong to nanometer scope and the thickness of some section is not more than $1 \mathrm{~nm},{ }^{23}$ moreover, there are much molecular level cavity in the HTBE structure. The nanometer size and ellipsoid-like shape of HTBE also result in lower hydromechanical vol-
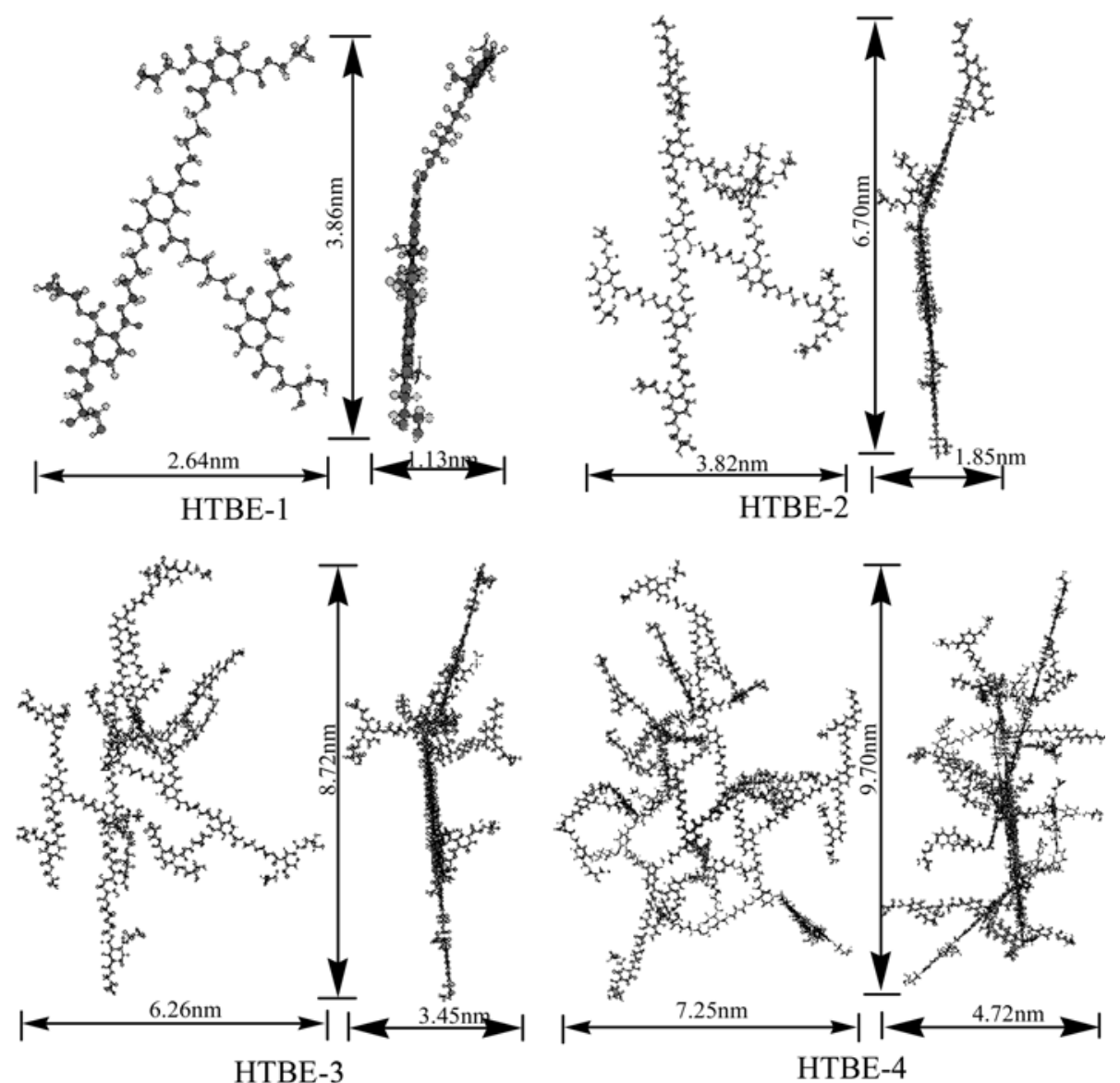

Figure 10. Simulation structure and shape of HTBE- $n(n=1,2,3,4)$. 


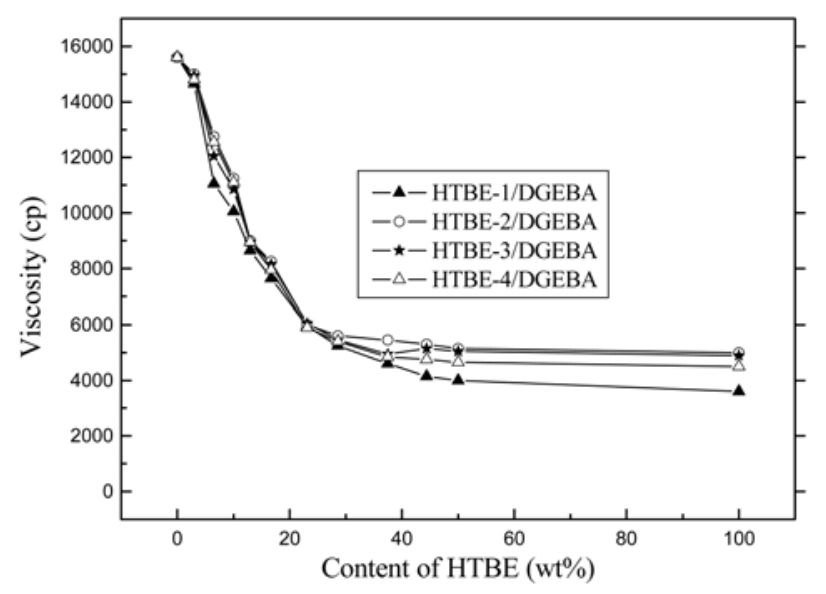

Figure 11. Effect of the content and molar mass of HTBE on the viscosity of hybrid resin.

ume than does stick-like shape of linear polymer. Moreover, the dense branched structure, which results in a low amount of intra- and intermolecular entanglements, allows good flow and inherent relative low viscosity.

Hyperbranched epoxy resin HTBE were added into bisphenol-A epoxy resin (DGEBA), and the effect of the content and molar mass of HTBE on the viscosity of HTBE/DGEBA hybrid resin was studied and the result was shown in Figure 11.

From Figure 11, the viscosity of HTBE/DGEBA hybrid resins decrease sharply with the increase of HTBE. Moreover, the viscosity of hybrid resins containing 15 20 wt\% HTBE is only 4,000 5,000 cp which is about 1/3 1/4 that of the viscosity of DGEBA (15,600 cp). So the functional hyperbranched epoxy resin can be used as a reactive thinner, and hopefully it may be widely applied in the fields of thermosetting resins and environmental-friendly resins.

\section{Conclusions}

The TMA and BEG monomers can be successfully used to synthesize carboxyl ended hyperbranched polymers (HTB) by a pseudo one-step method. Low viscosity and low epoxy equivalent weight hyperbranched epoxy resin (HTBE) also can be prepared by the reaction between carboxyl ended hyperbranched polymers and ECH. FTIR, ZAB and ${ }^{1} \mathrm{H}$ NMR measurements confirm that the reaction of TMA and BEG has taken place. The DB of HTB is calculated by ${ }^{1} \mathrm{H}$ NMR-minus spectrum technology. The number-average degree of polymerization and the molar mass of the HTB are calculated by "Recursive Probability Approach". Characteristics of HTBE, including molecular size, shape, epoxy equivalent weight and viscosity are obtained by molecular simulation and relevent measurements.
Acknowledgements. The authors gratefully acknowledge the financial support of the National Postdoctoral Science Foundation of China (No.20070420773), Science \& Technology Chenguang Young Project of Wuhan, China (No.200850731406), the Natural Science Foundation of South-central University for Nationalities, China (No. YZZ06012) and Open foundation of Guangdong Province key laboratory of high performance \& functional polymer materials.

\section{References}

(1) R. Mezzenga, L. Boogh, and J. A. E. Manson, Comp. Sci. Tech., 61, 787 (2001).

(2) B. P. Kent and B. Louis, WO9619537 (1996).

(3) W. J. Feast and X. Wang, Chin. J. Polym. Sci., 20, 585 (2002).

(4) T. Emrick, H. T. Chang, and J. M. J. Fréchet, Macromolecules, 32, 6380 (1999).

(5) T. Emrick, H. T. Chang, and J. M. J. Fréchet, Polym. Bull., 45, 1 (2000).

(6) T. Emrick, H. T. Chang, and J. M. J. Fréchet, J. Polym. Sci. Part A: Polym. Chem., 38, 4850 (2000).

(7) C.G. Gong and J. M. J. Fréchet, Macromolecules, 33, 4997 (2000).

(8) Y. Ishida, K. Yokomachi, M. Seino, T. Hayakawa, and M. Kakimoto, Macromol. Res., 15, 147 (2007).

(9) V. Coessens, J. Pyun, and P. J. Miller, S. G. Gaynor, and K. Matyjaszewski, Macromol. Rapid Commum., 21, 103 (2000).

(10) R. J. Varley and T. Wendy, Polym. Int., 53, 69 (2004).

(11) B. Louis, B. Pettersson, and J. A. E. Månson, Polymer, 40, 2249 (1999).

(12) T. Emrick, H. T. Chang, and J. M. J. Fréchet, J. Polym. Sci. Part A: Polym. Chem., 38, 4850 (2000).

(13) D. H. Zhang and D. M. Jia, J. Appl. Polym. Sci., 101, 2504 (2006).

(14) D. H. Zhang and D. M. Jia, Polym.-Plas. Tech. Eng., 45, 1005 (2006).

(15) D. H. Zhang and D. M. Jia, Eur. Polym. J., 42, 711 (2006).

(16) Y. C. Ning, Structural identification of organic compounds and organic spectroscopy, second edition, Beijing, 2000.

(17) C. J. Hawker and J. M. J. Fréchet, J. Am. Chem. Soc., 112, 7638 (1990).

(18) D. Y. Yan, A. H. E. Mueller, and K. Matyjaszewski, Macromolecules, 30, 7024 (1997).

(19) A. Reisch, H. Komber, and B. Voit, Macromolecules, 40, 6846 (2007).

(20) A. Fradet and M. Tessier, Macromolecules, 39, 6238 (2006).

(21) E. Žagar, M. Huskic, and M. Žigon, Macromol. Chem. Phys., 208, 1379 (2007).

(22) J. M. J. Fréchet, C. J. Hawker, I. Gitsov, and J. W. Leon, J. M. S.-Pure Appl. Chem., A33, 1399 (1996).

(23) K. K. Jena, K. V. S. N. Raju, B. Prathab, and T. M. Aminabhavi, J. Phys. Chem. B, 111, 8801 (2007). 